\title{
Paideusis
}

\section{Science and Epistemology: Philosophical Implications}

\section{Frederick S. Ellett Jr. and David P. Ericson}

Volume 5, Number 2, 1992

URI: https://id.erudit.org/iderudit/1073346ar

DOI: https://doi.org/10.7202/1073346ar

See table of contents

Publisher(s)

Canadian Philosophy of Education Society

ISSN

0838-4517 (print)

1916-0348 (digital)

Explore this journal

Cite this article

Ellett Jr., F. \& Ericson, D. (1992). Science and Epistemology: Philosophical Implications. Paideusis, 5(2), 3-14. https://doi.org/10.7202/1073346ar 


\title{
Science and Epistemology: Philosophical Implications
}

\author{
Frederick S. Ellett Jr., Faculty of Education, The University of \\ Western Ontario, London, Ontario
}

\section{David P. Ericson, Graduate School of Education, U.C.L.A., Los Angeles}

As educators, our considered view about scientific epistemology will affect our position on its role and emphasis in a well-rounded education; as citizens, it will affect our judgment about its place in policy formulation and evaluation. Also, our thoughts about its epistemology are intimately related to what we think about about scientific rationality, since for many, science serves as a paradigm case of rational activity. And perhaps most important will be the implications for our views on the nature of philosophy itself.

The general point we wish to develop is that many well-known conceptions of the epistemology of science need serious revision. The goals of science-especially the physical sciences, the forms of objectivity, and the relationship between science and truth require serious qualification, modification, and, in some places, outright rejection. The discussions by such philosophers of education as Black, Hamlyn, Hirst, Peters, and Scheffler (just to begin an interesting list) fail to reflect the insights and understandings produced by philosophers of science in the last decade or so. The paper starts by criticizing the views of Scheffler, in part, because they are fairly widely known. The paper concludes by suggesting that Dewey anticipated the most plausible account of inquiry.

It is hard to read current educational research journals without finding an article on the epistemology of science and the implications for educational research. Most of the articles, however, continue to repeat the criticisms of the logical empiricist's view of science, and they usually fail to provide any detailed alternative view.

In a recent and quite surprising article, Miller and Fredericks attempt to show that educational research can overcome "the problems" of incommensurability and untranslatability. Their conclusion rests on the premise that, since there are not any educational theories, then there are not any such problems! They also assert that all the talk about epistemology is rather misdirected because all educational researchers really agree on the appropriate standards and criteria (e.g., reliability, validity, the weight of the evidence, sampling, the rules of deductive and inductive inference, and triangulation). The irony of the paper is that it concludes that educational research is not subject to some typical logical empiricist problems by invoking a milder, or more modest, logical empiricist view of scientific theories and standards. ${ }^{1}$ In our judgment, Miller and Fredericks have not really understood the depth of the problems facing the logical empiricist (a point to which we will return). In a paper that clearly understands how deep the problems go, Howe and Eisenhart put forward an unhelpful alternative view based on the early 1980's "pragmatic" views of Rorty. For example, Howe and Eisenhart advise the educational researcher that the data collection techniques employed ought to fit-in the sense of being suitable for answering-the research question entertained. ${ }^{2}$

The limitations of logical empiricism have been clearly presented by 
many researchers. What is needed now is a more detailed alternative account of scientific thinking that will overcome the profound problems of logical empiricism.

We present some of the basic tenets of what we take to be the most promising account of scientific thinking-the decision-theoretic approach. For such an approach, the form of scientific thinking-in the so-called theoretical knowledge domain-is the same as the form of practical reasoning. Practical reasoning involves deciding what to do in a given context, where risk is involved and there often is a conflict of non-fixed, epistemic values. Furthermore, the decision-theoretic approach belongs to an evolutionary naturalistic approach in which the metaphilosophy becomes a key feature-there is no First (a priori) Philosophy.

\section{II}

In order to make the points in a sharp and contrasting fashion, we explicate the views of Scheffler, a well-known philosopher of education. In criticizing his view, we present an alternative and, in our judgment, a more promising approach.

Scheffler is concerned about the "objectivity" of our scientific claims as well as our everyday claims. He holds that the only plausible account of scientific theories and so on is one that affords them cognitive significance as being bearers of truth-values and ontic import. ${ }^{3}$ Scheffler maintains that

the structural terms, e.g., "theory," "confirms," "explains," "evidence," have much wider applications than those in which they refer to elements of the developed sciences; for example, they all apply to situations of everyday life and to those depicted in detective stories. ${ }^{4}$

Thus, Scheffler holds that one can use the simple examples which belong to everyday life or the common-sense world to illuminate the issues and problems of physics and chemistry. As he asserts, "the line between general epistemology and the philosophy of science seems to have disappeared." In a very strong sense, then, "science grows out of common-sense and is continuous with it." 5 Indeed, in his later book, Science and Subjectivity, Scheffler continues this theme when he considers "the epistemology of objectivity," in which the central issue of the relationship between knowledge and reality is pursued by resolving the "basic dilemma between coherence and certainty" using examples from everyday life and natural language usage. ${ }^{6}$ The "basic problem" in accounting for our everyday and scientific knowledge claims is that everyone accepts that any account must be logically coherent but logical coherence as the sole constraint is not enough. Certainty in the form of foundations would solve the problem, but every account of certainty turns out to be ultimately untenable. Thus, Scheffler rejects any foundational account and he rejects a C.I. Lewis kind of sense-data account of our cognitive achievements-an account subject to the problems of the earlier logical positivism. ${ }^{7}$ He rightly argues that something more than logical coherence is needed to account for and to justify our everyday and our scientific knowledge claims. But he still approaches the remaining issues using everyday-life and natural language examples. For Scheffler, science is the search for truth where 
the concepts "scientific knowledge," "truth," "independent reality," and "objectivity" are tightly interwoven. And scientific objectivity is bound tightly to the objectivity of the common-sense world view.

Although Scheffler has said that he was pleased that his discussion of Kuhn's writings had received wide attention, he holds that the discussion should not overshadow his treatment of "the major problem" facing both general epistemology and the philosophy of science, that of treating the opposition of logical coherence and certainty to develop an account of the contact between knowledge and reality. ${ }^{8}$ Using examples drawn from everyday life, he searches for an additional constraint to supplement logical coherence afforded by the rules of deductive logic. Following an early suggestion by Goodman, Scheffler claims that this constraint comes in the form of "intrinsic credibility" or "probability judgments":

They may be thought of as representing our varied inclinations to affirm given statements as true or assert them as scientifically acceptable; equivalently, they may be construed as indicating the initial claims we recognize statements to make upon us, at any given time, for inclusion within our cognitive systems. ${ }^{9}$

"Initial credibility" is to be differentiated from the relative use of "probability" in which the probability of a sentence is determined relative to certain other statements. ${ }^{10}$ Scheffler admits the term is a bit unclear, but he asserts:

It is enough that we find ourselves now impelled, in varying degrees, to affirm and retain [certain statements], seeking to satisfy as best we can the current demands of all. That these current demands vary for different, though equally consistent statements, and that we can distinguish, even roughly, the credibility-preserving properties of alternative coherent systems, suffices to introduce a significant limitation upon [logical] coherence. ${ }^{11}$

Thus, the credibility claims, and the need to preserve the overall credibility of the set of beliefs, provide the non-arbitrary and clearly relevant additional constraint.

The early logical positivists relied on the rules of deductive logic supplemented with certain foundations secured in various ways. Once the plausibility of the certain foundations was undermined, it became a pressing matter to supplement the deductive rules of logic with some inductive ones. In large measure, the later logical empiricist philosophers enlarged the stock of logical rules. Scheffler has made a similar enlargement. We agree with him that something like credibility claims do and should play an important part in accounting for our scientific knowledge claims. Nonetheless, Scheffler needs to show how one can actually use the rules of deductive logic and the preservation of credibility claims to legitimate our knowledge. He does correctly show that, from the fact that it is logically possible that we are in error, it does not follow we lack knowledge. ${ }^{12}$ It can also be shown that, from the fact there is some empirical chance that we are in error, it does not follow we lack knowledge. The sceptic could and should grant these points. But the sceptic still wants to be shown what the scope of knowledge is and how we obtain it. Scheffler just does not try to show how our knowledge can be legitimated by means of the rules of deductive logic and the credibility claims. But to address this problem squarely, Scheffler needs to get much more precise about the "credibility claims." Is he 
maintaining that all of us have the same credibility demands? Is this plausible? And if we do not "make" the same credibility claims, although each of us can constrain his own set of beliefs, how are we to regard the different credibility claims of others? If each of us had fairly different credibility claims, why should we expect to agree on the same knowledge claims?

One can and should be more specific. What are the constraints on the "credibility claims" themselves? (Of course, there is the [holistic] overall credibility-preserving constraint.) Would Scheffler accept the de Finetti view that the "credibility claims" themselves must form a probability measure (and, thereby, a "personalist" view of credal probability) or would he accept the extreme, subjectivist view of probability which is held by Popper (where a "subjectivist" denies that the probability claims form a probability measure)? ${ }^{13}$ Without specific answers to these questions, Scheffler is in no position to legitimate our knowledge claims in science and everyday life.

Let us suppose, however, that Scheffler would follow Carnap in maintaining that these are general principles of deductive and inductive logic (where inductive logic includes the "personalistic" credibility claims). Such general principles should be applicable no matter who the agents are or the circumstances under which they are deliberating. Such general logical principles impose constraints on the ways agents ought to think which are universally applicable regardless of circumstance. ${ }^{14}$ As Levi has pointed out, in such a Carnapian framework, the objectivity of scientific inquiry is made to stand or fall with the existence of a fairly powerful and fixed system of principles applicable to all agents on all occasions. ${ }^{15}$ Such universal principles (i.e., the rules of inductive and deductive logic) allegedly can be used to derive the more specific methods, reasons, and beliefs of a particular inquiry at a particular time. The more specific methods, reasons, and beliefs, of course, are subject to change and revision, given further observations and the rules of logic.

In the following passage, Scheffler, too, draws the distinction between the more specific methods and the general (universal) criteria or principles:

Rationality cannot be taken simply as an abstract and general ideal. It is embodied in multiple evolving traditions, in which the basic condition holds that issues are resolved by reference to reasons, themselves defined by principles purporting to be impartial and universal. ${ }^{16}$

For Scheffler, the specific methods and reasons found in an evolving tradition are rational because they can be "defined" and defended by the received set of observations and the impartial and universal principles-the principle of logical coherence and the principle of credibility preservation. The universal principles are characterized in a logically-formal manner. Since they do not build-in any empirically-contingent background theory or claims, the principles are equally applicable to all possible inquiries and investigations. The universal principles may be called the ultimate principles of rationality; such principles are essentially formal. His view, therefore, has two major difficulties. First, he needs to articulate and defend a specific conception of "credibility" and a specific principle of credibility preservation. Given his general stance, one can expect that the relevant concepts will be characterizable in a formal manner (and that the principle will constrain the set of beliefs as a whole). (As we have already noted, there are several alternatives open to him.) Second, 
Scheffler needs to show how one can actually get determinately to the specific beliefs, methods, and reasons from the general rules (and one's stock of credible observations). Much of Scheffler's work has been directed to showing what does not follow from certain claims.

These issues are complex and extremely difficult. Many of those who have studied so-called inductive-logic (an area of inquiry, one should note, filled with controversy) doubt whether one can actually use any such rules to defend determinately our scientific and everyday knowledge claims. As Levi notes:

As pragmatists have recognized for a long time, contextual considerations may be invoked in appraising steps taken at various stages of inquiry. We need not rest content with deductive logic and the thin gruel that inductive logic has to offer. ${ }^{17}$

In a similar vein, Boyd concludes that Kuhn and others have established that judgments of (Goodmanian) projectibility and degrees of confirmation are quite profoundly dependent upon the theories that make up the existing theoretical tradition or paradigm. ${ }^{18}$ Formal accounts of scientific thinking fail to acknowledge how one's best theoretical understanding of the world affects one's epistemic values and strategies. In our view, then, Scheffler has not provided a justification of our everyday knowledge and our scientific knowledge and it is doubtful that one can with so meagre a set of formal resources.

Levi's earlier work tried to build upon Popper's insight that there is a value-conflict between securing true theories and securing theories that are "interestingly informative" about the world. ${ }^{19}$ Rescher has recently explicated this tradeoff in a particularly insightful manner by showing how the typical sceptic is so [abnormally] concerned about risking error that the sceptic can learn little or nothing about the world. ${ }^{20}$ For Levi and Rescher, there appears to be no logical, formal principle (or rule) for setting the tradeoff rate, yet a person's tradeoff rate is an integral part of his/her epistemic rationality. With the work of Levi and Rescher, one sees the basic form of the decision-theoretic approach-there are competing epistemic values to be pursued and the compromises (tradeoffs) always involve risks. Scientific thinking is seen to be a form of practical reasoning where one is trying to decide what theory to accept and in what manner.

Levi's later work continues and extends the earlier approach. Yet it still faces major problems. Although it may strike the reader as too complex, the approach still does not make adequate room for all important scientific values: explanatory depth, explanatory precision, predictive scope, predictive precision, heuristic power, simplicity, technical applicability, technical reliability, sociocultural control, and so on. ${ }^{21}$ And it should be clear that such scientific values are not fixed and given once and for all, but rather that they are developed as the inquiry continues to go on. For example, the shift from a conception of deterministic to probabilistic causation became defensible as it was realized that the reconceptualization allowed one to solve several of the major problems facing theoretical inquiry. Nonetheless, we believe that one should regard Levi's work as providing a simplified model that is useful for exploring certain questions in an analytical framework. One should not expect the simplified model to capture all of the important features of scientific thinking. A second kind of major problem is that Levi's account suggests that scientific activity can be modelled as a calculative rationality. Levi's account suggests that, after due allowances 
are made for certain contextual features, the rest can be reduced to an algorithm. But there is as yet no reason to suppose that such a calculative conception will prove adequate.

The major value of Levi's work, perhaps, is that has presented a promising kind of approach to epistemology. The traditional approach emphasizes arguments, conclusions, and logical rules of inference. In a decision-theoretic approach, theory acceptance (and there are many ways to accept a theory) is modelled as a choice relative to certain utilities (scientific or epistemic values) and to expectations and risks (beliefs about the world and our place in it). Writers such as Levi, Rescher, and Hooker can readily admit that there may be no fixed, unique scientific method and that method is a function of one's theories, but they can still maintain that there is an adequate, unique theory of prospective methodology (i.e., the decision-theoretic account which can allow a specific role for contextual factors). ${ }^{22}$

In our tolerant interpretation of Kuhn, we believe his early work was actually exploring (albeit in a confused manner) the decision-theoretic approach. ${ }^{23}$ We regard Kuhn's later comments about "predictive accuracy, simplicity, scope, and compatibility with other specialties" to be a regressive step away from the decision-theoretic account, for such comments fail to mention the general structure of acceptance as modelled in decision-theoretic terms. ${ }^{24}$ Scheffler, too, seems to miss the possible shift to the decision-theoretic model for, when he responds to Kuhn's views, he asserts that Kuhn merely reintroduces the older critical concepts under new labels "so that we have a plausible but no longer novel view." 25 And although Scheffler sees that Kuhn wants to talk about "values" instead of "reasons," Scheffler just fails to see the possible shift to the decision-theoretic approach to epistemology. ${ }^{26}$

What Kuhn was dimly getting at, and what Levi, Hooker, and Rescher explicitly argue, is that theoretical knowledge (theory acceptance, and so on) has the same form as practical rationality-one's epistemology is modelled on a decision-theoretic account. The promising accounts by Levi, Hooker, and Rescher should be seen as our best attempts to make sense of scientific activities given our present understanding of ourselves and the world. Our inquiry may lead one to regard the decision-theoretical accounts not as calculation-devices but as accounts that emphasize the currently perceived relevant features to which scientific judgement should attend. Our best attempts, therefore, may well lead us to construe scientific activity as a kind of "practical argument" in which various features are judged to be relevant and to carry a particular weight. And whether any feature is given a particular weight is a contingent (empiricalin-the-wide-sense) matter. ${ }^{27}$

This leads us to the final, important characteristic of the evolutionary, naturalistic decision-theoretic approach: its metaphilosophy is wholly non- $a$ priori. The founding members of logical positivism and many later logical empiricists did share at least one belief with the Rationalist philosophers: they held that there is some kind of a priori truth about the world, even if the kind of a priori truth does not concern content but rather concerns the universal laws of logic-the universal principles of deductive and inductive logic. If they were such universal principles, then quite readily they could legitimately govern all inquiry. And hence, there could be a First (A Priori) Philosophy.

Once one comes to accept the view that applied logic has some kind of an 
empirical status, then the defence of any particular set of formal or informal rules must be justified as a contingent matter within the ongoing inquiry. The rules will be seen as being conducive to furthering the epistemic values of the inquiry and will be regarded as trustworthy until further notice. When the pertinent formal logic for a domain of inquiry has some kind of empirical status, there remains little hope of defending $a$ priori any set of formal rules to govern or constrain all inquiry. With no a priori rules and with no certain foundations, there is no first philosophy that is prior to all forms of inquiry. Rules, standards, and criteria remain, but they must be defended as being conducive to furthering the ongoing inquiry. And there still is a philosophical account of the scientific activities, yet it is no longer an a priori activity but a contingent form of inquiry itself.

Putnam put it this way in the early 1980's:

In 1951, W.V. Quine published a paper titled "Two Dogmas of Empiricism." From that time on, these has been a steady erosion in philosophical confidence in the notion of an a priori truth. .. .In general, we have to admit that consideration of simplicity, overall utility, and plausibility may lead us to give up something that we formerly regarded as a priori, and that this is reasonable. ${ }^{28}$

Putnam readily accepts that philosophy has become anti-a prioristic. But this change has disturbed many others. As Putnam noted:

What makes this line seem so disturbing is that it makes our standards of rational acceptability, justification, and ultimately of truth, dependent on standards of similarity which are clearly the product of our biological and cultural heritage. ${ }^{29}$

What is disturbing is that these positions seem to leave the way open to the extreme relativist or sceptic. ${ }^{30}$

In a more recent essay, Boyd, a kind of scientific realist, has written:

Like the causal theorist of perception or other "naturalistic" epistemologists, the scientific realist must deny that the most basic principles of inductive inference or justification are defensible $a$ priori. In a word, the scientific realist must see epistemology as an empirical science. ${ }^{31}$

And he went on to add the more general point:

If these controversial consequences of a thorough-going realist conception of scientific knowledge are sound, then it would be hard to escape a still more controversial conclusion: philosophy is itself a sort of empirical science. ${ }^{32}$

We believe Boyd's remarks also apply to any naturalistic philosopher. In our view, Hooker has provided the most comprehensive overview of philosophy and meta-philosophy. ${ }^{33}$ And his articulation of the evolutionary naturalistic realistic view presents a quite plausible view. For the naturalistic realist, there is no First Philosophy in the traditional sense. The naturalistic realist prefers to state the meta-philosophy before the philosophy to inform

... us that philosophical doctrine is not to be constructed a priori, with some intuitively fixed goals (fixed, e.g., in terms of their "neatness," completeness, security-making, etc.) which are set in advance, but rather it is to aim at capturing our current understanding of ourselves and our world as contained in common experience and refined in science. ${ }^{34}$ 
And Hooker underscores the essential naturalistic stance:

... .whatever else may be said, this much is sure: it is the collective, historical human experience that counts. ${ }^{35}$

So, contrary to Scheffler's position that there is an a priori way to constrain inquiry in terms of either content or formal rules, the naturalistic position is that scientific epistemology and philosophy itself are forms of contingent inquiry. The deep and profound mistake of both the early logical positivist and the later logical empiricist was to construe scientific epistemology and philosophy as an a priori inquiry. Scheffler's "modest empiricism" has made the same mistake. A proper understanding of scientific thinking frees both science and philosophy from thinking they need a First Philosophy.

\section{III}

We would like to suggest briefly that Dewey's view of inquiry fully anticipated the recent work by such philosophers as Hooker, Levi, Rescher, Putnam, Rorty, and Margolis. ${ }^{36}$ Indeed, the revival of interest in Dewey's thought can be traced to the following key Deweyan ideas. It should not be surprising that the philosophers mentioned above often call themselves "pragmatists."

First, it is well-known that Dewey was against all kinds of dualisms, and especially the theoretical versus practical knowledge dualism. ${ }^{37}$ The recent work by Levi, Hooker, and Rescher provides strong reasons to believe that scientific activities have a single form - the form of practical rationality.

Second, it is well-known that Dewey was strongly opposed to all forms of a priori constraints on inquiry. Indeed, Dewey intentionally used the term "intelligence" to accomplish two purposes. In the first, Dewey wanted to contrast "intelligence" from what one important school of past ages called "reason" or "pure intellect," where "reason" is regarded as the highest organ or faculty for laying hold of ultimate, universal, and a priori truths. In the second, Dewey used the term to designate "the great and ever-growing methods of observation, experiment and reflective reasoning which have in a very short time revolutionized the physical and, to a considerable degree, the physiological conditions of life, but which have not as yet been worked out for application to what is itself distinctively and basically human."38 Dewey maintained that the reconstruction to be undertaken is not that of applying "intelligence" as something ready-made. Nor is it even to be seen as fixed, final, and certain. And although Dewey said that science is a "process" and a pursuit with new methods, Dewey clearly rejected the view that there is a Platonic Essence to science or that there is a fixed, final, immutable method. ${ }^{39}$ Science invents, develops, and reorganizes as it faces the tests of experience. It comes to understand better itself and the world as it "grows." Not only do we learn more about the world, we also learn more about how we learn. 40

The most important passages, however, are contained in the "new introduction" to Reconstruction in Philosophy written in 1948. Dewey began by waming the reader that " $[t]$ his introduction is written in the spirit of the [1920] text." 41 The intervening events had convinced Dewey that "Reconstruction of Philosophy is a more suitable title than Reconstruction in Philosophy" (em- 
phasis in original). The 1920 text had urged that philosophers apply "the scientific method" to moral philosophy. But by 1948, Dewey had recognized that the whole of philosophy had to be reconceived. As he put it:

Furthermore, the intervening events have sharply defined, have brought to a head, the basic postulate of the [1920] text: namely, that the distinctive office, problems, and subject matter of philosophy grow out of stresses and strains in the community life in which a given form of philosophy arises, and that, accordingly, its specific problems vary with the changes in human life that are always going on and that at times constitute a crisis and a tuming point in human history. ${ }^{42}$ (Our emphasis)

Dewey still wanted to "carry over into any inquiry into human and the moral subjects the kind of method by which understanding of physical nature has been brought to its present pitch." 43 But here one needs to be clear about what he regarded as so special about inquiry about physical nature-so special that Dewey regarded it as "the most revolutionary discovery yet made." 44 Dewey noted that

Philosophical doctrines which disagreed about virtually everything else were at one in the assumption that their distinctive concem as philosophy was to search for the immutable and ultimate-that which is-without respect to the temporal or spatial. 45

The most revolutionary discovery is "that natural science is forced by its own development to abandon the assumption of fixity and to recognize that for what it is actually 'universal' in process." 46 In the next paragraph, Dewey drew out the moral implication:

The supposed fact that morals demand immutable, extra-temporal principles, standards, norms, ends, as the only assured protection against moral chaos can, however, no longer appeal to natural science for its support nor expect to justify by science its exemption of morals (in practice and in theory) from considerations of time and place-that is, from processes of change. . All that is needed is acceptance of the view that moral subject matter is also spatially and temporally qualified. ${ }^{47}$

In an analogous fashion, Dewey has already elaborated the general philosophical implication in this quotation. For dramatic effect, we shall say that the supposed fact that philosophy demands immutable, extra-temporal principles, standards, norms, ends, as the only assured protection against philosophical chaos (scepticism?) can, however, no longer appeal to natural science for its support, nor expect to justify by science its exemption of philosophy in practice and in theory from considerations of time and place--that is, from processes of change. All that is needed is acceptance of the view that philosophical subject matter is also spatially and temporally qualified. To repeat Putnam's phrase, philosophy should become radically anti-a prioristic.

If Hooker, Levi, Margolis, Putnam, and Rescher can serve as reliable indicators, then philosophy is indeed becoming anti-a prioristic. We believe that Dewey had anticipated the views which these philosophers have elaborated and defended in great detail. 
To this point, we have been concerned with the nature of scientific epistemology and the closely related notion of objectivity-as-shared-judgment. Our critique of Scheffler must stop short of dealing with the ontological sense of objectivity that involves matters of scientific realism, truth, and the real world. We can only assert that Scheffler's arguments do not adequately address the problems-at-hand. Further, one need not follow the earlier Rorty in seeing pragmatism as opposed to scientific realism and the related ontological notion of truth. ${ }^{48}$ We accept the Levi, Hooker, Margolis, and Rescher kind of pragmatism that claims that although philosophy cannot "by itself" legitimate science, it can (by working-from-within) show why knowledge claims are trustworthy and, therefore, authoritative. To our surprise and delight, Rorty now appears to share our position. ${ }^{49}$

In our view, Dewey, the pragmatist, can most plausibly be interpreted as a non-reductive, non-eliminist, scientific realist who grants the fully emergent properties of persons and their cultural worlds, where the latter are not seen as closed systems. And, as Hooker (and others) can teach us, although scientific realism is not required for explaining scientific inquiry, it provides the most plausible account of the achievements of science (as compared with, say, the constructive-empiricist account). Although Dewey never pursued the issues with such detail, it is still fair to say that Dewey anticipated the general form of the account.

So far we have argued that Dewey had, in effect, anticipated some of the most promising developments in recent accounts of scientific thinking. Can the same be argued for moral thinking? Yes, indeed. Dewey would argue by analogy with scientific thinking: there are no foundations, no fixed universals, and no fixed methods. All is up for intelligent and reasonable evaluation and, where necessary, revision. Thus, Dewey could be seen as having anticipated Rawls' notion of moral justification as reflective equilibrium. Unlike Rawls, however, Dewey would see reflective equilibrium as itself dynamic and in flux. Dewey argued in precisely this manner. ${ }^{50}$ 


\section{Notes}

${ }^{1}$ S.I. Miller and M. Fredericks, "Postpositivist Assumptions and Educational Research: Another View," Educational Researcher, 20(4), 1991, 2-8.

${ }^{2} \mathrm{~K}$. Howe and M. Eisenhart, "Standards for Qualitative (and Quantitative) Research: A Prolegomenon," Educational Researcher, 1(4), 1990, 2-9 (see especially 6-7).

${ }^{3}$ I. Scheffler, Anatomy of Inquiry (Indianapolis: Bobbs-Merrill, 1963), 15.

${ }^{4}$ Ibid., 13.

${ }^{5}$ Ibid., 13-14.

6I. Scheffler, Science and Subjectivity (2nd Ed.) (Indianapolis: Hackett Publishing, 1982), ix, 99, 114.

${ }^{7}$ Scheffler pursues the same approach in his Conditions of Knowledge (Chicago: Scott, Foresman, and Company, 1965).

${ }^{8}$ Scheffler, Science and Subjectivity, ix.

${ }^{9}$ Ibid., 116.

${ }^{10}$ Ibid., 117.

${ }^{11}$ Ibid., 118. See also, 119-120. The tentativeness of these remarks found in the Anatomy of Inquiry (324) is absent in Science and Subjectivity.

${ }^{12}$ Scheffler, Conditions of Knowledge, 29-39.

${ }^{13}$ I. Levi, The Enterprise of Knowledge (Cambridge, MA: M.I.T. Press, 1980), 77-79, 426-7.

14Ibid., 426. Scheffler, Anatomy of Inquiry, op. cit., 6.

15. Levi, op. cit., 427.

16. Scheffler, Reason and Teaching (Indianapolis: Bobbs-Merrill, 1973), $76,79$.

17I. Levi, op. cit., 428. See also C.A. Hooker, A Realistic Theory of Science (Albany: State University of New York Press, 1987), 144.

${ }^{18}$ R. Boyd, "The Current Status of Scientific Realism," in J. Leplin (Ed.), Scientific Realism (Berkeley, CA: University of California, 1984).

${ }^{19}$ I. Levi, Gambling With Truth (Cambridge, MA.: M.I.T. Press, 1967).

${ }^{20}$ N. Rescher, Rationality (Oxford: Clarendon Press, 1988), Chapter 4.

${ }^{21}$ Hooker, op. cit. 246, 302, 312. An important part of Hooker's view is that the naturalistic philosophers' metaphilosophy is contingent (see Chapters 3 and 8). In a related naturalistic view, Lycan argues that no formal probability relation can exhaust epistemological justifiability which is fundamentally linked to maximizing the explanatory coherence of one's total belief system. See William Lycan, Judgement and Justification (Cambridge: Cambridge University Press, 1988), Chapter 7.

${ }^{22}$ I. Levi, The Enterprise of Knowledge, op. cit.; C. Hooker, op. cit., 143-150, 389-91; and N. Rescher, op. cit., 1988.

${ }^{23}$ T. Kuhn, The Structure of Scientific Revolutions (1st Ed.) (Chicago: University of Chicago Press, 1962).

${ }^{24}$ T. Kuhn, ibid., (2nd Ed., 1970), 206, and T. Kuhn, "Reflections on My Critics," in I. Lakatos and A. Musgrave (Eds.), Criticism and the Growth of Knowledge (Cambridge: Cambridge University Press, 1970), 261.

${ }^{25}$ Scheffler, Science and Subjectivity, op. cit., 129.

${ }^{26}$ Ibid., 130. See also, I. Scheffler, "Pragmatism as a Philosophy," in Inquiries: Philosophical Studies of Language, Science, and Learning (In- 
dianapolis, Indiana: Hackett Publishing, 1986). Here Scheffler defends the ideal of a universal method.

${ }^{27}$ For an early statement about how the models exhibit features, see A. Gibbard, and W.L. Harper, "Counterfactuals and Two Kinds of Expected Utility," in C.A. Hooker, J.J. Leach, and E.F. McClennen (Eds.), Foundations and Applications of Decision Theory (Bordrecht, Holland: D. Reidel Publishing, 1978), Vol, 1, 125-62.

${ }^{28} \mathrm{H}$. Putnam, Reason, Truth and History (Cambridge, MA.: Cambridge University Press, 1981), 82-3.

${ }^{29}$ Ibid., 94.

${ }^{30}$ In our view, there are really no reasons to be disturbed, but we address such anxieties in another place. op. cit..

${ }^{31}$ R. Boyd, "The Current Status of Scientific Realism," J. Leplin (Ed.),

${ }^{32}$ Ibid., 65.

${ }^{33}$ Hooker, op. cit., Chapter 4.

34Ibid., 94.

35 Ibid., 96.

36. Margolis, Pragmatism Without Foundations (London: Basil Blackwell, 1986).

${ }^{37}$ There are many sources. We cite John Dewey's Reconstruction in Philosophy (Enlarged Edition) (Boston: Beacon Press, 1948), xxii.

${ }^{38}$ Ibid., viii-xi.

${ }^{39}$ Ibid., xiii, xvii, xxix, xxxiii, 54.

${ }^{40}$ Ibid. Contrast xiii, xvii with xxxviii-xxxix (and viii); and 95-6.

${ }^{41}$ Ibid., v. See also pp. xvii and $\mathrm{xx}$ (our emphasis).

${ }^{42}$ Ibid., v.

${ }^{43}$ Ibid., ix.

${ }^{44}$ Ibid., xiii. See also xxxiv and $\mathrm{xl}$.

45Ibid., xiii.

46Ibid. More than one of Dewey's contemporaries misunderstood Dewey's basic insights. For an interesting example, see W.H. Kilpatrick, Philosophy of Education (New York: Macmillan, 1951).

${ }^{47}$ Ibid.

${ }^{48}$ It should be said that although Rorty is a major interpreter of Dewey, we would argue that we need not accept Rorty's claim that philosophy cannot legitimate knowledge claims but must rest content merely saying that $i s$ the way we do things - there is no normative work for philosophy to do. See Rorty's Philosophy and the Mirror of Nature (Princeton, N.J.: Princeton University Press, 1979), and Consequences of Pragmatism (Minneapolis: University of Minnesota Press, 1982.)

${ }^{49}$ See Rorty's Objectivity, Relativism, and Truth (Cambridge: Cambridge University Press, 1991). See also Dewey's The Quest for Certainty (New York: Capricorn Books, 1960), Chapter VII.

${ }^{50}$ John Dewey, ibid., Chapter X, "The Construction of the Good." 